\title{
Suppression of Sebum Production and Accumulation by $\beta$-Cryptoxanthin Due to the Inhibition of the Expression of Diacylglycerol Acyltransferase-1 and Perilipin in Hamster Sebocytes
}

\author{
Takashi Sato $^{1 \#}$, Yoshiyuki Shirakura ${ }^{2}$, Katsuyuki Mukai ${ }^{2}$, Akira Ito ${ }^{1}$ \\ ${ }^{1}$ Department of Biochemistry and Molecular Biology, School of Pharmacy, Tokyo University of Pharmacy and Life Sciences, Ha- \\ chioji, Tokyo, Japan; ${ }^{2} \mathrm{R} \&$ D Center, Unitika Ltd., Kyoto, Japan. \\ Email: " satotak@toyaku.ac.jp
}

Received December $13^{\text {th }}, 2012$; revised January $15^{\text {th }}, 2013$; accepted January $24^{\text {th }}, 2013$

\begin{abstract}
Background: Acne vulgaris is characterized by the enhancement of sebaceous lipogenesis and sebum secretion, and apart from retinoids and some natural products there are few effective anti-acne agents that directly suppress sebum production and accumulation in sebaceous glands. Objective: We examined the effects of $\beta$-cryptoxanthin $(\beta$-CRX), which is a carotenoid pigment most abundant in Citrus unshiu Marcovich (Satsuma mandarin orange) and plays a role as a Vitamin A precursor on sebum production and accumulation in hamster sebaceous gland cells (sebocytes). Materials and methods: The regulation of sebum production was examined by the measurement of triacylglycerols (TGs), the major sebum component, and oil red $\mathrm{O}$ staining in insulin-differentiated hamster sebocytes. The expression of diacylglycerol acyltransferase-1 (DGAT-1), a rate-limiting enzyme of TG biosynthesis, and perilipin 1 (PLIN1), a lipid storage droplet protein, was analyzed using real-time PCR and Western blotting. Results: Hamster sebocytes constitutively produced TGs during cultivation and the production of TGs was enhanced by insulin treatment. Both constitutive and insulin-enhanced TG productions were dose- and time-dependently inhibited by $\beta$-CRX as well as 13-cis retinoic acid. In addition, the gene expression of DGAT- 1 was suppressed by $\beta$-CRX in the sebocytes. Furthermore, the insulin-enhanced sebum accumulation as lipid droplets was reduced in the $\beta$-CRX-treated cells. Moreover, $\beta$-CRX was found to suppress the gene expression and production of PLIN1 in insulin-differentiated hamster sebocytes. Conclusions: These results provide novel evidence that $\beta$-CRX is an effective candidate for acne therapy by its ability to exert dual inhibitory actions against DGAT-1-dependent TG production and PLIN1-mediated lipid-droplet formation in hamster sebocytes.
\end{abstract}

Keywords: $\beta$-Cryptoxanthin; Sebocytes; Triacylglycerol Biosynthesis; Diacyglycerol Acyltransferase; Perilipin; Lipid-Droplet Formation; Sebum

\section{Introduction}

The pathogenesis of acne, a common inflammatory skin disease [1,2], is characterized by: 1) excess sebum production in sebaceous glands; 2) the formation of microcomedones, which is closely associated with the hyperkeratinization of the follicular wall and infundibulum; 3) the hyperproliferation of Propionibacterium acnes $(P$. acnes); and 4) the induction of inflammatory reactions such as the acceleration of cytokine production and the biosynthesis of arachidonic acid metabolites in keratinocytes, sebocytes, and invaded inflammatory cells $[3,4]$. The aggravation and duration of the inflammation are

${ }^{*}$ Conflict of interest: The authors have no conflict of interest to declare. ${ }^{\#}$ Corresponding author. likely to result in acne scar that causes a psychological and social impact in the patient's quality of life [4].

Sebum production in acne lesions has been reported to be increased by $5 \alpha$-dihydrotestosterone, insulin, insulin-like growth factor 1, and prostaglandins [5-9]. In addition, the biosynthesis of sebum components such as triacylglycerols (TGs) and sapienic acids is regulated by diacylglycerol acyltransferase (DGAT), a rate-limiting enzyme of TG synthesis $[6,10]$, and $\Delta 6$ desaturase (FADS2) [11], respectively, in human and hamster sebocytes. Furthermore, we have previously reported that the production of perilipin (PLIN), a lipid storage droplet protein, is augmented in differentiated hamster sebocytes and localized on the surface of intracellular lipid droplets, 
indicating that perilipin is a differentiation marker in hamster sebocytes [12]. On the other hand, retinoic acids such as tretinoin (all-trans retinoic acid; atRA) and isotretinoin (13-cis retinoic acid; 13-cisRA) have been topically and/or systemically used for acne therapy $[13,14]$. They have been reported to exhibit comedolytic, antiinflammatory, and anti-lipogenetic actions in sebaceous glands and pilosebaceous units in humans, rats, and hamsters in vivo and in vitro [14-19]. However, the use of retinoids in acne therapy has been limited in acceptance because of adverse effects such as skin irritation, scaling, and teratogenicity [13].

$\beta$-Cryptoxanthin ( $\beta$-CRX), a carotenoid pigment most abundant in Citrus unshiu Marcovich (Satsuma mandarin orange), has been reported to exhibit multiple disease preventive actions; e.g. anti-tumorigenic, anti-obesity, antiatherogenic, and immunopotentiative ones [20-23]. In addition, carotenoids such as $\beta$-CRX and $\beta$-carotene have been reported to be present in the blood of people from different countries including Japan, which is associated with some health benefits $[22,24]$. Indeed, epidemiologic studies have shown that higher intakes or blood levels of $\beta$-CRX result in a reduced risk of lung cancer and rheumatoid arthritis development [25-27]. On the other hand, it has also been reported that low plasma level of Vitamin $\mathrm{A}$ is associated with the development and aggravation of acne [28]. In addition, $\beta$-CRX is a vitamin A precursor, which is oxidatively cleaved to vitamin A by $\beta$-carotene 15,15'-dioxygenase [29], and can be stably stored in some tissue for several months [30]. Taken together with a recent report by Shirakura et al. [31] where $\beta$-CRX inhibits the intracellular lipid-droplet formation in mouse 3T3-L1 adipocytes, we hypothesize that, instead of retinoids such as atRA and 13-cisRA, $\beta$-CRX is an effective candidate for acne therapy by modulating sebaceous lipogenesis. However, it is not fully understood whether $\beta$-CRX directly suppresses sebum production and accumulation in sebaceous gland cells (sebocytes) or not.

In the present study, we demonstrated that $\beta$-CRX doseand time-dependently inhibited the production and intracellular accumulation of sebum in insulin-differentiated hamster sebocytes. Furthermore, the $\beta$-CRX-mediated inhibition of sebum production and accumulation is closely associated with the transcriptional suppression of DGAT1 and PLIN1, respectively, in differentiated hamster sebocytes.

\section{Materials and Methods}

\subsection{Cell Culture and Treatment}

Hamster sebocytes $\left(2.4 \times 10^{4}\right.$ cells $\left./ \mathrm{cm}^{2}\right)$ [32] were plated onto 96 -well multiplates, $35-\mathrm{mm}$ or $100-\mathrm{mm}$ diameter culture dishes (Becton Dickinson, Tokyo, Japan) and then cultured for $24 \mathrm{~h}$ in DMEM/F12 (Invitrogen, Carlsbad, CA) supplemented with $6 \%$ heat-denatured fetal bovine serum (Nichirei Biosciences Inc., Tokyo, Japan), $2 \%$ human serum (C-C Biotech Co., Valley Center, CA), $0.68 \mathrm{mM} \mathrm{L}$-glutamine (Invitrogen), and recombinant human epidermal growth factor $(10 \mathrm{nM})$ (Progen Biotechnik GmbH, Heidelberg, Germany) to achieve complete cell adhesion as previously described $[6,18]$. The hamster sebocytes were treated every two days for up to 8 days with or without $\beta$-CRX (purity $\geq 95 \%$; Shikoku Yashima Pure Chemicals, Tokushima, Japan) (Figure 1) or 13-cisRA (Sigma Chemical, St. Louis, MO) in the presence or absence of a sebocyte-differentiation inducer, insulin (10 nM) (Sigma Chemical) [12] in DMEM/F12 supplemented with heat-denatured fetal bovine serum, human serum, and $L$-glutamine. In this series of experiments, hamster sebocytes were used as far as the 3rd passage level.

\subsection{Analyses of Sebum Production and Accumulation}

After treating sebocytes with $\beta$-CRX, 13-cisRA, and/or insulin, the cells were subjected to the quantification of TGs, the major sebum component, using Liquitech TG-II (Roche Diagnostics, Tokyo, Japan) as previously described [12]. The amounts of intracellular TGs were calculated using an authentic trioleinate-standard solution $(0.6 \mathrm{mg} / \mathrm{ml})$. Intracellular DNA content was measured using salmon sperm DNA (6.25 - $100 \mathrm{mg} / \mathrm{ml})$ and 3,5diaminobenzoic acid dihydrochloride (Sigma Chemical). For the analysis of intracellular sebum accumulation, oil red $\mathrm{O}$ staining was performed. Briefly, the cells were washed once with $\mathrm{Ca}^{2+}$ - and $\mathrm{Mg}^{2+}$-free phosphate-buffered saline $[\mathrm{PBS}(-)]$ and fixed with $4 \%$ paraformaldehyde (Wako Pure Chemicals, Osaka, Japan) diluted with PBS(-) for $1 \mathrm{~h}$ at room temperature. The cells were washed with distilled $\mathrm{H}_{2} \mathrm{O}$ and then stained with $0.3 \%$ oil red $\mathrm{O}$ (Sigma Chemical) in isopropanol:distilled $\mathrm{H}_{2} \mathrm{O}$ $\left(3: 2\right.$, vol:vol) at $37^{\circ} \mathrm{C}$ for $15 \mathrm{~min}$. The stained cells were washed with distilled $\mathrm{H}_{2} \mathrm{O}$, and then viewed with a light microscope furnished with a digital camera (Olympus Optical Co., Tokyo, Japan).

\subsection{Real-Time PCR}

For the quantification of DGAT-1 and PLIN1 mRNA, total RNA was isolated from cells using ISOGEN (Nippon Gene, Toyama, Japan) and then the aliquot of RNA (500 ng) was subjected to reverse transcriptase reaction

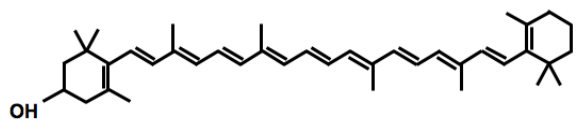

Figure 1. Chemical structure of $\beta$-cryptoxanthin $(\beta$-CRX). 
for the synthesis of cDNA using a PrimeScript RT reagent Kit (Takara Bio, Shiga, Japan) according to the manufacturer's instructions. Aliquots (an equivalent of $2.5 \mathrm{ng}$ of total RNA) of the transcript were subjected to real-time PCR using SYBR Premix Ex Taq II (Takara Bio) and the following specific primers: human DGAT-1 (NM_012079); 5'-TCTACAAGCCCATGCTTCGAC-3' (sense) and 5'-GGACGCTCACCAGGTACT-3' (antisense), hamster PLIN1 (AB091681); 5'-ACCTTGCT GGATGGAGACC-3' (sense) and 5'-CCAGGACCTTG TCTGAAGT-3' (antisense), and hamster glyceraldehyde-3-phosphate dehydrogenase (GAPDH) (X52123); 5'-CAGAACATCATCCCTGCAT-3' (sense) and 5'-TA GGAACACGGAAGGCCAT-3' (antisense) as previously described [33]. The amplification cycle was performed at $94^{\circ} \mathrm{C}$ for $5 \mathrm{~s}$ and $60^{\circ} \mathrm{C}$ for $30 \mathrm{~s}$ using a Thermal Cycler Dice Real Time System TP-800 (Takara Bio). The obtained threshold cycle (CT) value for DGAT-1 and PLIN1 was normalized by that for GAPDH, and the relative expression level was expressed as the mean value of the control as 1 .

\subsection{Western Blot Analysis}

The harvested cell lysate (50 $\mu \mathrm{g}$ protein) was subjected to Western blot analysis using $12.5 \%$ acrylamide gel as previously described [33]. The membrane was reacted with rabbit anti-(human PLIN1) IgG, which was customized by Operon Biotechnologies (Tokyo, Japan). To evaluate the level of $\beta$-actin as an internal control, the harvested cell lysates (50 $\mu \mathrm{g}$ protein) were similarly subjected to Western blot analysis using rabbit anti-(human $\beta$-actin) IgG (Medical \& Biological Laboratories, Nagoya, Japan). Immunoreactive PLIN1 and $\beta$-actin were visualized with Amersham enhanced chemiluminescence-Western blotting detection reagents (GE Healthcare BioSciences, Tokyo, Japan) according to the manufacturer's instructions. Relative amounts of PLIN1 protein against $\beta$-actin were quantified by densitometric scanning using an Image Analyzer LAS-1000 Plus (GE Healthcare), and the relative expression level was expressed as the mean value of the control as 1 .

\subsection{Statistical Analysis}

A one-way ANOVA was used for the statistical analysis, and then the Fisher test was applied when multiple comparisons were performed.

\section{Results}

\subsection{Inhibition of TG Production and DGAT-1 Gene Expression by $\beta$-CRX in Hamster Sebocytes}

Since hamster sebocytes constitutively produce TGs dur- ing cultivation in vitro [32], we first examined the effect of $\beta$-CRX on constitutive TG production in cultured hamster sebocytes. As shown in Figure 2(A), $\beta$-CRX was found to decrease the level of TGs in a dose-dependent manner $(70 \%$ inhibition at $10 \mu \mathrm{M})$. In addition, the sebocyte differentiation inducer, insulin $(10 \mathrm{nM})$, was found to enhance the production of TGs in hamster sebocytes, and the enhanced level of TGs was dose-dependently decreased by $\beta$-CRX (72\% inhibition at 10 $\mu \mathrm{M})$. Furthermore, a similar decrease in TG level was time-dependently observed in hamster sebocytes treated with $\beta$-CRX as well as 13-cis RA (Figure 3), as we previously reported $[18,34]$. On the other hand, the gene expression of DGAT-1 was constitutively detectable, and was found to be increased in response to insulin treatment in hamster sebocytes $(7.7 \pm 3.9$ fold, $\mathrm{p}<0.05)$ (Figure 2(B)). In addition, $\beta$-CRX was found to suppress the gene expression of DGAT-1 in both the insulin-untreated and treated hamster sebocytes (52\% and $88 \%$ inhibition, respectively) (Figure 2(B)). Therefore, these results suggest that $\beta$-CRX inhibits the production of TGs due to the suppression of DGAT-1 expression in hamster sebocytes.

\subsection{Suppression of Sebum Accumulation by Decreasing Gene Expression and Production of Perilipin in Hamster Sebocytes}

As the intracellular accumulation of sebum as lipid-droplets has been reported to be due to the increase of TG production in differentiated hamster sebocytes [32], oil red $\mathrm{O}$ staining revealed that the lipid-droplet formation was augmented in the insulin-differentiated hamster sebocytes (Figures 4(B) vs. (A)). In addition, the enhanced sebum accumulation was found to be abolished by adding $\beta$-CRX $(10 \mu \mathrm{M})$ (Figures 4(C) vs. (B)). On the other hand, perilipin, a lipid-droplet surface protein, has been reported to play an important role in the formation of intracellular lipid droplets in differentiated adipocytes, steroidogenic cells, and sebocytes $[12,35]$. As $\beta$-CRX inhibited sebum accumulation as lipid droplets (Figure 4), we examined whether $\beta$-CRX influenced the production of PLIN1 in hamster sebocytes. As shown in Figure $\mathbf{5}$, the production of PLIN1 was barely detectable in insulin-untreated sebocytes, but was augmented by insulin treatment. In addition, $\beta$-CRX was found to dose-dependently suppress the insulin-enhanced production of PLIN1 in hamster sebocytes. Furthermore, both basal and insulin-augmented levels of PLIN1 mRNA were found to be decreased in the $\beta$-CRX-treated cells (Figure 6). Thus, these results suggest that the suppression of PLIN1 production by $\beta$-CRX is associated with the inhibition of sebum accumulation in differentiated hamster sebocytes. 


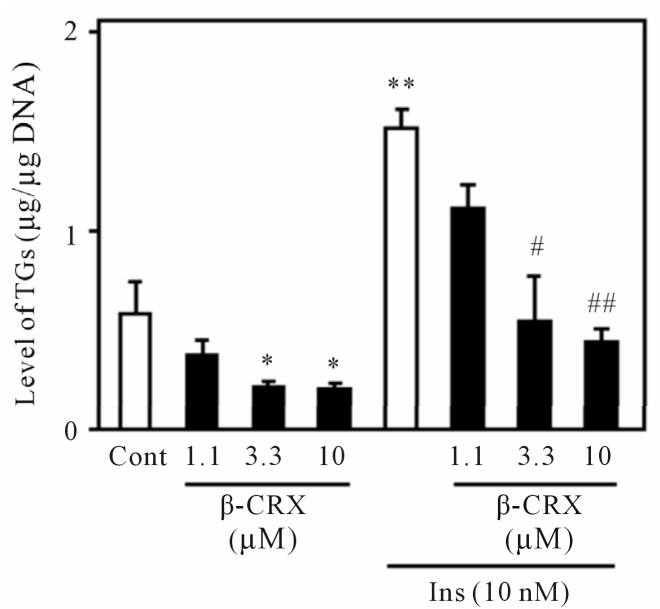

(A)

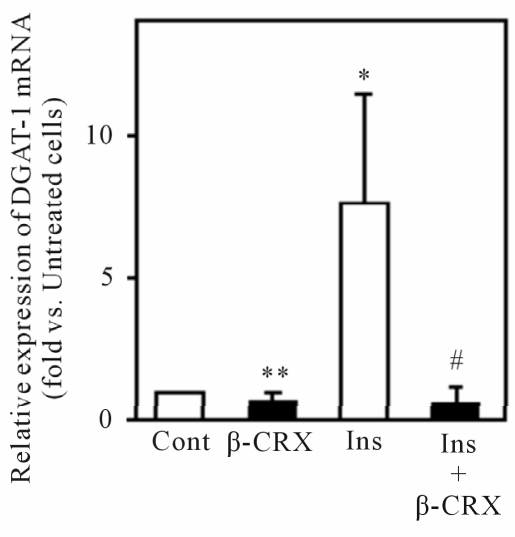

(B)

Figure 2. The decrease of intracellular TG level by $\beta$-CRX in hamster sebocytes. Hamster sebocytes at the 3rd passage were treated every two days for 8 days with or without $\beta$-CRX $(1.1-10 \mu \mathrm{M})$ in the presence or absence of insulin (Ins) (10 nM). A: The harvested cell lysate was subjected to the measurement of intracellular TG level as described in the Materials and Methods. B: Isolated RNA (an equivalent of $2.5 \mathrm{ng}$ of total RNA) from the cells was subjected to the analysis of DGAT-1 mRNA expression as described in the Materials and Methods. Data are shown as mean \pm SD of three dishes. ${ }^{*}$ and ${ }^{* * *}$, significantly different from untreated cells (Cont) $\left(\mathrm{p}<0.05\right.$ and 0.01 , respectively). ${ }^{\#}$ and ${ }^{\# \#}$, significantly different from insulin (Ins) $(10 \mathrm{nM})$-treated cells $(\mathrm{p}<0.05$ and 0.01 , respectively).

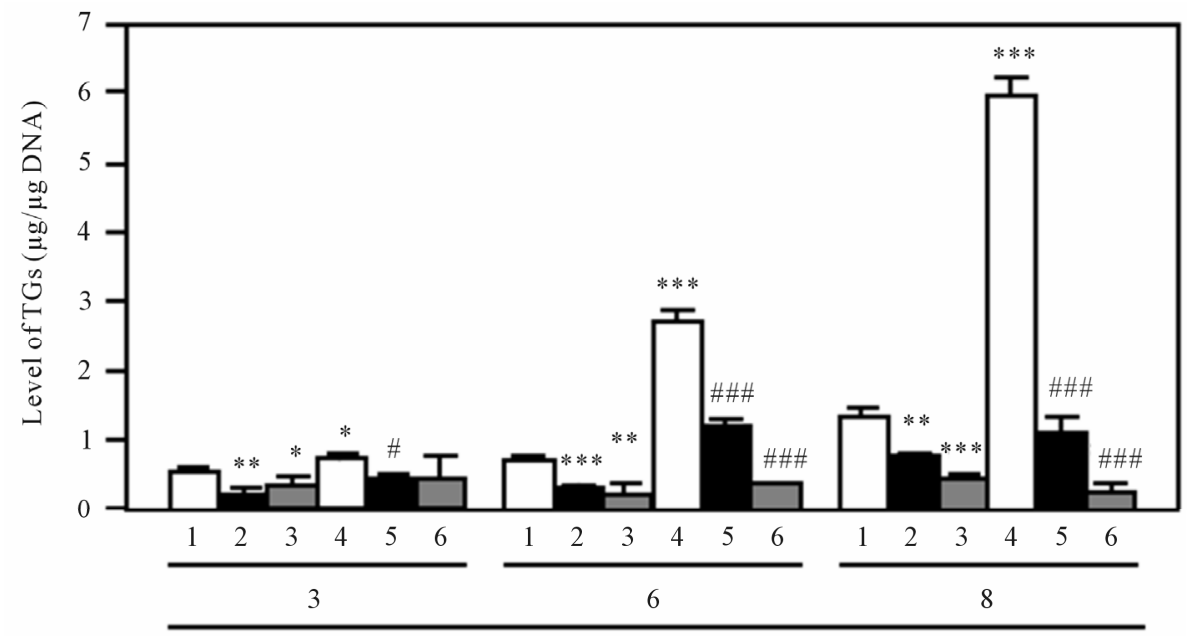

Culture periods (days)

Figure 3. Time-dependent inhibition of TG production by $\beta$-CRX in hamster sebocytes. Hamster sebocytes at the 3rd passage were treated every two days for up to 8 days with or without $\beta$-CRX $(10 \mu M)$ or 13 -cisRA $(1 \mu M)$ in the presence or absence of insulin (10 $\mathrm{nM})$, and then the intracellular level of TGs was measured. Data are shown as mean \pm SD of three dishes. Lane 1, untreated cells; Lane 2, $\beta$-CRX (10 $\mu \mathrm{M})$-treated cells; Lane 3, 13-cisRA (1 $\mu \mathrm{M})$-treated cells; Lane 4 , insulin (10 $\mathrm{nM})$-treated cells; Lane 5, cells treated with insulin $(10 \mathrm{nM})$ and $\beta$-CRX $(10 \mu \mathrm{M})$; and Lane 6 , cells treated with insulin $(10$ $\mathrm{nM})$ and 13-cisRA $(1 \mu \mathrm{M}) .{ }^{*},{ }^{* *}$, and ${ }^{* * *}$, significantly different from untreated cells $\left(\mathrm{p}<0.05,0.01\right.$, and 0.001 , respectively). ${ }^{\#}$

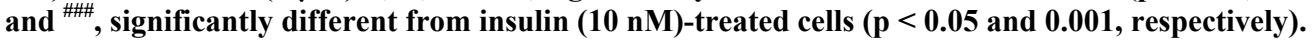

\section{Discussion}

We demonstrated that $\beta$-CRX suppresses the production of TGs and the gene expression of DGAT-1 in differentiated hamster sebocytes. Our previous study showed that the decrease of TG production by both 13-cisRA and atRA is closely related to that of DGAT activity as well as the DGAT-1 transcript in differentiated hamster sebocytes [18]. In addition, Harris et al. (2011) [36] reported that DGAT is required for not only TG synthesis but also lipid droplet formation in adipocytes from DGAT knockout mice. Therefore, these results provide novel evidence that $\beta$-CRX inhibits de novo synthesis of TGs 


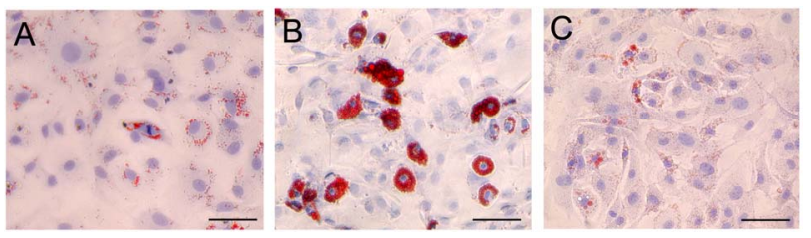

Figure 4. $\beta$-CRX decreases sebum accumulation in insulindifferentiated hamster sebocytes. Hamster sebocytes treated with insulin (10 $\mathrm{nM})$ and/or $\beta$-CRX $(10 \mu \mathrm{M})$ as shown in Figure 2 were subjected to oil red $O$ staining for the analysis of intracellular sebum accumulation as described in the Materials and Methods. A: untreated cells; B: insulin (10 $\mathrm{nM})$-treated cells; and $\mathrm{C}$ : cells treated with insulin $(10 \mathrm{nM})$ and $\beta$-CRX $(10 \mu \mathrm{M})$. Bars: $50 \mu \mathrm{m}$.

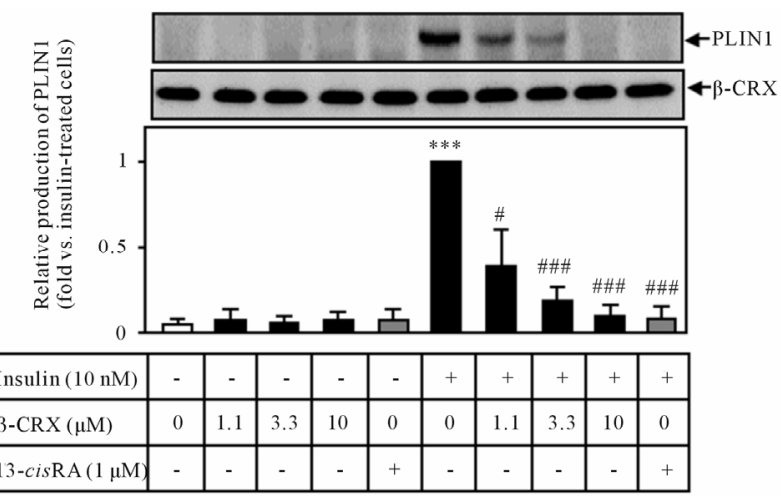

Figure 5. $\beta$-CRX and 13-cisRA suppress the production of PLIN1 in insulin-differentiated hamster sebocytes. Cell lysate $(50 \mu$ protein) prepared from hamster sebocytes treated every two days for 8 days with insulin (10 $\mathrm{nM}), \beta$-CRX (1.1 - $10 \mu M)$, and/or 13-cisRA $(1 \mu M)$ was subjected to Western blot analysis for PLIN1 and $\beta$-actin as described in the Materials and Methods. Data are shown as mean \pm SD of four independent experiments. ***, significantly different from untreated cells $(p<0.001)$. ${ }^{\#}$ and ${ }^{\# \#}$, significantly different from insulin $(10 \mathrm{nM})$-treated cells $(\mathrm{p}<0.05$ and 0.001 , respectively).

by suppressing DGAT-1 expression, which may in turn participate in the inhibition of lipid droplet formation in differentiated sebocytes. Furthermore, taken together with previous reports that TGs from sebaceous glands are a source of nutrition of $P$. acnes [1,3], $\beta$-CRX-decreased TG production is very likely to indirectly result in the prevention of $P$. acnes proliferation in acne lesions.

The PAT-family of intracellular lipid storage droplet proteins such as PLIN1-5 has been reported to play important roles in the regulation of TG storage and lipolysis in adipocytes and steroidogenic cells [35]. Our previous study showed that PLIN1 localizes to the surface of intracellular sebum-droplets in differentiated hamster sebocytes [12]. In the present study, we found that not only intracellular lipid-droplet formation but also the gene expression and production of PLIN1 was suppressed by $\beta$-CRX in differentiated hamster sebocytes. A similar

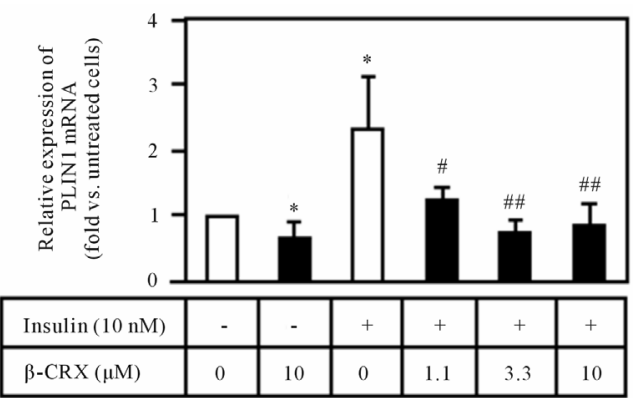

Figure 6. Suppression of PLIN1 mRNA expression by bCRX in insulin-differentiated hamster sebocytes. Isolated RNA (an equivalent of $2.5 \mathrm{ng}$ of total RNA) from the cells treated with insulin $(10 \mathrm{nM}), \beta$-CRX $(1.1-10 \mathrm{mM})$, and/or 13-cisRA (1 mM) as shown in Figure 5 was subjected to the analysis of PLIN1 mRNA expression as described in the Materials and Methods. Data are shown as mean \pm SD of four different experiments. *, significantly different from untreated cells $(p<0.05) .{ }^{\#}$ and ${ }^{\# \#}$, significantly different from insulin $(10 \mathrm{nM})$-treated cells $(\mathrm{p}<0.05$ and 0.01 , respectively).

inhibition of lipid-droplet formation has been reported to be observed in $\beta$-CRX-treated mouse 3T3-L1 adipocytes [31]. Therefore, the $\beta$-CRX-inhibition of lipid-droplet formation is likely to include the transcriptional suppression of PLIN1 production in hamster sebocytes. Moreover, intracellular lipid-droplet formation has been reported to be associated with the protein kinase A (PKA)-dependent phosphorylation of PLIN, which facilitates the hormonesensitive lipase-mediated lipolysis of neutral lipid droplets in adipocytes [37,38]. We previously reported that neither the level of cyclic AMP (cAMP) nor PKA activity was augmented by 13-cisRA [18], of which its suppressive action against sebum accumulation is similar to that of $\beta$-CRX in differentiated hamster sebocytes. However, $\beta$-carotene, which is structurally and functionally similar to $\beta$-CRX [39], has been reported to increase the level of cAMP and PKA activity in human pulmonary adenocarcinoma cells and epithelial cells from small airways and pancreatic ducts $[40,41]$. Thus, $\beta$-CRX may also influence the phosphorylation of PLIN1, which is coordinately associated with the abolishment of lipiddroplets in differentiated hamster sebocytes. Further experiments are needed to clarify these hypotheses.

The development of comedones has been related to the enhancement of sebum production in sebaceous glands, under which various lipogenetic signaling through androgen and/or insulin-like growth factor 1/insulin pathways is activated $[42,43]$. In the inflamed acne lesions resulting from comedogenesis, the expression and activation of PPAR $\gamma$ have been reported to be augmented and closely associated with the aggravation of acne pathology [44,45]. Shirakura et al. [31] reported that $\beta$-CRX does not affect peroxisome proliferators activating receptor $\gamma$ 
$(\operatorname{PPAR} \gamma)$ activation. We have preliminarily demonstrated that $\beta$-CRX did not alter the PPAR $\gamma$ ligand, troglitazone-augmented production of TGs and PLIN1 production in hamster sebocytes (Sato $\mathrm{T}$ and Ito $\mathrm{A}$, unpublished data). Therefore, the inhibitory actions of $\beta$-CRX against sebum production and storage in sebocytes may at least partially account for the beneficial efficacy in the prevention of comedogenesis in acne lesions under noninflammatory conditions.

Carotenoids split into two groups; xanthophylls and carotenes [21]. Xanthophylls such as $\beta$-CRX exist as an ester form with fatty acids in fruits or vegetables $[46,47]$. In addition, xanthophyll esters have been reported to be present in human skin, where the xanthophylls are reesterified following absorption [48]. Since the blood concentration of $\beta$-CRX has been reported to be higher than that of $\beta$-carotene or lycopene [47], it is suggested that $\beta$-CRX is easily absorbed and accumulated in the skin, where it may behave as Vitamin A for the control of cutaneous functions. Taken together with a report of El-Akawi et al. [28] that low plasma levels of Vitamin A are associated with acne development and aggravation, therefore, the supplementation of $\beta$-CRX is likely to be effective for the prevention of acne or acne maintenance.

In conclusion, our findings provide novel evidence that $\beta$-CRX is an effective candidate for acne therapy by inhibiting not only sebaceous lipogenesis but also sebum accumulation against insulin-differentiated hamster sebocytes, in which acne pathology is at least partly mimicked in vitro. Furthermore, these findings may contribute to a novel understanding of the molecular mechanisms of dietary carotenoids in the maintenance of skin barrier functions.

\section{Acknowledgements}

This work was supported by a Grant-in-Aid for Scientific Research (C) (\#22590506). We wish to thank Dr. K. Kitamura and Miss. M. Kuwata for their technical assistance.

\section{REFERENCES}

[1] H. Pawin, C. Beylot, M. Chivot, M. Faure, F. Poli, J. Revuz and B. Dréno, "Physiopathology of Acne Vulgaris: Recent Data, New Understanding of the Treatments," European Journal of Dermatology, Vol. 14, No. 1, 2004, pp. 4-12.

[2] C. C. Zouboulis, A. Eady, M. Philpott, L. A. Goldsmith, C. Orfanos, W. C. Cunliffe and R. Rosenfield, "What Is the Pathogenesis of Acne?" Experimental Dermatology, Vo. 14, No. 2, 2005, pp. 143-152. doi:10.1111/j.0906-6705.2005.0285a.x

[3] H. C. Williams, R. P. Dellavalle and S. Garner, "Acne Vulgaris," Lancet, Vol. 379, No. 9813, 2012, pp. 361-

\section{2. doi:10.1016/S0140-6736(11)60321-8}

[4] I. Kurokawa, F. W. Danby, Q. Ju, X. Wang, L. F. Xiang, L. Xia, W. Chen, I. Nagy, M. Picardo, D. H. Suh, R. Ganceviciene, S. Schagen, F. Tsatsou and C. C. Zouboulis, "New Developments in Our Understanding of Acne Pathogenesis and Treatment," Experimental Dermatology, Vol. 18, No. 10, 2009, pp. 821-832. doi:10.1111/j.1600-0625.2009.00890.x

[5] R. L. Rosenfield, A. Kentsis, D. Deplewski and N. Ciletti, "Rat Preputial Sebocyte Differentiation Involves Peroxisome Proliferator-Activated Receptors," Journal of Investigative Dermatology, Vol. 112, No. 2, 1999, pp. 226232. doi:10.1046/j.1523-1747.1999.00487.x

[6] C. Iwata, N. Akimoto, T. Sato, Y. Morokuma and A. Ito, "Augmentation of Lipogenesis by 15 -Deoxy- $\delta^{12,14}$-Prostaglandin $\mathrm{J}_{2}$ in Hamster Sebaceous Glands: Identification of Cytochrome P-450-Mediated 15-deoxy- $\delta^{12,14}$-Prostaglandin $\mathrm{J}_{2}$ Production," Journal of Investigative Dermatology, Vol. 125, No. 5, 2005, pp. 865-872.

[7] T. Alestas, R. Ganceviciene, S. Fimmel, K. Müller-Decker and C. C. Zouboulis, "Enzymes Involved in the Biosynthesis of Leukotriene $\mathrm{B}_{4}$ and Prostaglandin $\mathrm{E}_{2}$ Are Active in Sebaceous Glands," Journal of Molecular Medicine, Vol. 84, No. 1, 2006, pp. 75-87. doi:10.1007/s00109-005-0715-8

[8] T. M. Smith, Z. Cong, K. L. Gilliland, G. A. Clawson and D. M. Thiboutot, "Insulin-Like Growth Factor-1 Induces Lipid Production in Human SEB-1 Sebocytes via Sterol Response Element-Binding Protein-1," Journal of Investigative Dermatology, Vol. 126, No. 6, 2006, pp. 12261232. doi: $10.1038 /$ sj.jid. 5700278

[9] N. R. Trivedi, K. L. Gilliland, W. Zhao, W. Liu and D. M. Thiboutot, "Gene Array Expression Profiling in Acne Lesions Reveals Marked Upregulation of Genes Involved in Inflammation and Matrix Remodeling," Journal of Investigative Dermatology, Vol. 126, No. 5, 2006, pp. 10711079. doi:10.1038/sj.jid.5700213

[10] A. Turkish and S. L. Sturley, "Regulation of Triglyceride Metabolism. I. Eukaryotic Neutral Lipid Synthesis: 'Many Ways to Skin ACAT or a DGAT'," American Journal of Physiology. Gastrointestinal and Liver Physiology, Vol. 292, No. 4, 2007, pp. G953-957.

[11] L. Ge, J. S. Gordon, C. Hsuan, K. Stenn and S. M. Prouty, "Identification of the $\Delta-6$ Desaturase of Human Sebaceous Glands: Expression and Enzyme Activity," Journal of Investigative Dermatology, Vol. 120, No. 5, 2003, pp. 707-714. doi:10.1046/j.1523-1747.2003.12123.x

[12] N. Akimoto, T. Sato, C. Iwata, M. Koshizuka, F. Shibata, A. Nagai, M. Sumida and A. Ito, "Expression of Perilipin A on the Surface of Lipid Droplets Increases along with the Differentiation of Hamster Sebocytes in Vivo and in Vitro," Journal of Investigative Dermatology, Vol. 124, No. 6, 2005, pp. 1127-1133. doi:10.1111/j.0022-202X.2005.23718.x

[13] A. Krautheim and H. P. Gollnick, "Acne: Topical Treatment," Clinics in Dermatology, Vol. 22, No. 5, 2004, pp. 398-407. doi:10.1016/j.clindermatol.2004.03.009

[14] J. B. Bikowski, "Mechanisms of the Comedolytic and 
Anti-Inflammatory Properties of Topical Retinoids," Journal of Drugs in Dermatology, Vol. 4, No. 1, 2005, pp. 4147.

[15] I. Tenaud, A. Khammari and B. Dreno, "In Vitro Modulation of TLR-2, CD1d and IL-10 by Adapalene on Normal Human Skin and Acne Inflammatory Lesions," Experimental Dermatology, Vol. 16, No. 6, 2007, pp. 500-506. doi:10.1111/j.1600-0625.2007.00552.x

[16] C. C. Zouboulis, B. Korge, H. Akamatsu, L. Q. Xia, S. Schiller, H. Gollnick and C. E. Orfanos, "Effects of 13-cisRetinoic Acid, All-trans-Retinoic Acid, and Acitretin on the Proliferation, Lipid Synthesis and Keratin Expression of Cultured Human Sebocytes in Vitro," Journal of Investigative Dermatology, Vol. 96, No. 5, 1991, pp. 792-797. doi:10.1111/1523-1747.ep12471782

[17] M. J. Kim, N. Ciletti, S. Michel, U. Reichert and R. L. Rosenfield, "The Role of Specific Retinoid Receptors in Sebocyte Growth and Differentiation in Culture," Journal of Investigative Dermatology, Vol. 114, No. 2, 2000, pp. 349-353. doi:10.1046/j.1523-1747.2000.00868.x

[18] T. Sato, A. Takahashi, M. Kojima, N. Akimoto, M. Yano and A. Ito, "A Citrus Polymethoxy Flavonoid, Nobiletin Inhibits Sebum Production and Sebocyte Proliferation, and Augments Sebum Excretion in Hamsters," Journal of Investigative Dermatology, Vol. 127, No. 12, 2007, pp. 27402748.

[19] A. M. Nelson, K. L. Gilliland, Z. Cong and D. M. Thiboutot, "13-cis Retinoic Acid Induces Apoptosis and Cell Cycle Arrest in Human SEB-1 Sebocytes," Journal of Investigative Dermatology, Vol. 126, No. 10, 2006, pp. 21782189. doi:10.1038/sj.jid.5700289

[20] A. J. Young and G. M. Lowe, "Antioxidant and Prooxidant Properties of Carotenoids," Archives of Biochemistry and Biophysics, Vol. 385, No. 1, 2001, pp. 20-27. doi:10.1006/abbi.2000.2149

[21] A. Matsumoto, H. Mizukami, S. Mizuno, K. Umegaki, J. Nishikawa, K. Shudo, H. Kagechika and M. Inoue, " $\beta$ Cryptoxanthin, a Novel Natural RAR Ligand, Induces ATP-Binding Cassette Transporters in Macrophages," Biochemical Pharmacology, Vol. 74, No. 2, 2007, pp. 256264. doi:10.1016/j.bcp.2007.04.014

[22] G. Maiani, M. J. Castón, G. Catasta, E. Toti, I. G. Cambrodón, A. Bysted, F. Granado-Lorencio, B. OlmedillaAlonso, P. Knuthsen, M. Valoti, V. Böhm, E. Mayer-Miebach, D. Behsnilian and U. Schlemmer, "Carotenoids: Actual Knowledge on Food Sources, Intakes, Stability and Bioavailability and Their Protective Role in $\mathrm{Hu}-$ mans," Molecular Nutrition and Food Research, Vol. 53 Suppl. 2, 2009, pp. S194-218. doi:10.1002/mnfr.200800053

[23] K. Takayanagi, S. Morimoto, Y. Shirakura, K. Mukai, T. Sugiyama, Y. Tokuji and M. Ohnishi, "Mechanism of Visceral Fat Reduction in Tsumura Suzuki Obese, Diabetes (TSOD) Mice Orally Administered $\beta$-Cryptoxanthin from Satsuma Mandarin Oranges (Citrus Unshiu Marc)," Journal of Agricultural and Food Chemistry, Vol. 59, No. 23, 2011, pp. 12342-12351. doi:10.1021/jf202821u

[24] M. Sugiura, H. Matsumoto, M. Kato, Y. Ikoma, M. Yano and A. Nagao, "Multiple Linear Regression Analysis of the Seasonal Changes in the Serum Concentration of $\beta$ Cryptoxanthin," Journal of Nutritional Science and Vitaminology, Vol. 50, No. 3, 2004, pp. 196-202. doi:10.3177/jnsv.50.196

[25] S. Männistö, S. A. Smith-Warner, D. Spiegelman, D. Albanes, K. Anderson, P. A. van den Brandt, J. R. Cerhan, G. Colditz, D. Feskanich, J. L. Freudenheim, E. Giovannucci, R. A. Goldbohm, S. Graham, A. B. Miller, T. E. Rohan, J. Virtamo, W. C. Willett and D. J. Hunter, "Dietary Carotenoids and Risk of Lung Cancer in a Pooled Analysis of Seven Cohort Studies," Cancer Epidemiology, Biomarkers and Prevention, Vol. 13, No. 1, 2004, pp. 4048. doi:10.1158/1055-9965.EPI-038-3

[26] J. M. Yuan, D. O. Stram, K. Arakawa, H. P. Lee and M. C. Yu, "Dietary Cryptoxanthin and Reduced Risk of Lung Cancer: The Singapore Chinese Health Study," Cancer Epidemiology, Biomarkers and Prevention, Vol. 12, No. 9, 2003, pp. 890-898.

[27] D. J. Pattison, D. P. Symmons, M. Lunt, A. Welch, S. A. Bingham, N. E. Day and A. J. Silman, "Dietary $\beta$-Cryptoxanthin and Inflammatory Polyarthritis: Results from a Population-Based Prospective Study," The American Journal of Clinical Nutrition, Vol. 82, No. 2, 2005, pp. 451455.

[28] Z. El-Akawi, N. Abdel-Latif and K. Abdul-Razzak, "Does the Plasma Level of Vitamins A and E Affect Acne Condition," Clinical and Experimental Dermatology, Vol. 31, No. 3, 2006, pp. 430-434. doi:10.1111/j.1365-2230.2006.02106.x

[29] T. M. Redmond, S. Gentleman, T. Duncan, S. Yu, B. Wiggert, E. Gantt and F. X. Cunningham Jr., "Identification, Expression, and Substrate Specificity of a Mammalian $\beta$-Carotene 15,15'-Dioxygenase," The Journal of Biological Chemistry, Vol. 276, No. 9, pp. 6560-6565. doi:10.1074/jbc.M009030200

[30] M. Sugiura, M. Kato, H. Matsumoto, A. Nagao and M. Yano, "Serum Concentration of $\beta$-Cryptoxanthin in Japan Reflects the Frequency of Satsuma Mandarin (Citrus unshiu Marc.) Consumption," Journal of Health Sciences, Vol. 48, No. 4, 2002, pp. 350-353. doi:10.1248/jhs.48.350

[31] Y. Shirakura, K. Takayanagi, K. Mukai, H. Tanabe and M. Inoue, " $\beta$-Cryptoxanthin Suppresses the Adipogenesis of 3T3-L1 Cells via RAR Activation," Journal of Nutritional Science and Vitaminology, Vol. 57, No. 6, 2011, pp. 426-431. doi:10.3177/jnsv.57.426

[32] T. Sato, N. Imai, N. Akimoto, T. Sakiguchi, K. Kitamura and A. Ito, "Epidermal Growth Factor and 1 $\alpha, 25$-Dihydroxyvitamin $\mathrm{D}_{3}$ Suppress Lipogenesis in Hamster Sebaceous Gland Cells in Vitro," Journal of Investigative Dermatology, Vol. 117, No. 4, 2001, pp. 965-970. doi:10.1046/j.0022-202x.2001.01516.x

[33] T. Sato, T. Shirane, N. Noguchi, M. Sasatsu and A. Ito, "Novel Anti-Acne Actions of Nadifloxacin and Clindamycin That Inhibit the Production of Sebum, Prostaglandin $\mathrm{E}_{2}$ and Promatrix Metalloproteinase-2 in Hamster Sebocytes," Journal of Dermatology, Vol. 39, No. 9, 2012, pp. 774-780. 
doi:10.1111/j.1346-8138.2012.01525.x

[34] K. Iinuma, T. Sato, N. Akimoto, N. Noguchi, M. Sasatsu, S. Nishijima, I. Kurokawa and A. Ito, "Involvement of Propionibacterium acnes in the Augmentation of Lipogenesis in Hamster Sebaceous Glands in Vivo and in Vitro," Journal of Investigative Dermatology, Vol. 129, No. 9, 2009, pp. 2113-2119. doi:10.1038/jid.2009.46

[35] A. R. Kimmel, D. L. Brasaemle, M. McAndrews-Hill, C. Sztalryd and C. Londos, "Adoption of PERILIPIN as a Unifying Nomenclature for the Mammalian PAT-Family of Intracellular Lipid Storage Droplet Proteins," Journal of Lipid Research, Vol. 51, No. 3, 2010, pp. 468-471. doi:10.1194/jlr.R000034

[36] C. A. Harris, J. T. Haas, R. S. Streeper, S. J. Stone, M. Kumari, K. Yang, X. Han, N. Brownell, R. W. Gross, R. Zechner and R. V. Farese Jr., "DGAT Enzymes Are Required for Triacylglycerol Synthesis and Lipid Droplets in Adipocytes," Journal of Lipid Research, Vol. 52, No. 4, 2011, pp. 657-667. doi:10.1194/jlr.M013003

[37] D. L. Brasaemle, B. Rubin, I. A. Harten, J. Gruia-Gray, A. R. Kimmel and C. Londos, "Perilipin A Increases Triacylglycerol Storage by Decreasing the Rate of Triacylglycerol Hydrolysis," The Journal of Biological Chemistery, Vol. 275, No. 49, 2000, pp. 38486-38493. doi:10.1074/jbc.M007322200

[38] H. Wang, L. Hu, K. Dalen, H. Dorward, A. Marcinkiewicz, D. Russell, D. Gong, C. Londos, T. Yamaguchi, C. Holm, M. A. Rizzo, D. Brasaemle and C. Sztalryd, "Activation of Hormone-Sensitive Lipase Requires Two Steps, Protein Phosphorylation and Binding to the PAT-1 Domain of Lipid Droplet Coat Proteins," The Journal of Biological Chemistery, Vol. 284, No. 46, 2009, pp. 3211632125. doi:10.1074/jbc.M109.006726

[39] M. Kato, Y. Ikoma, H. Matsumoto, M. Sugiura, H. Hyodo and M. Yano, "Accumulation of Carotenoids and Expression of Carotenoid Biosynthetic Genes during Maturation in Citrus Fruit," Plant Physiology, Vol. 134, No. 2, 2004, pp. 824-837. doi:10.1104/pp.103.031104

[40] H. A. Al-Wadei, T. Takahashi and H. M. Schuller, "Growth Stimulation of Human Pulmonary Adenocarcinoma Cells and Small Airway Epithelial Cells by $\beta$-Carotene via Ac- tivation of cAMP, PKA, CREB and ERK1/2," International Journal of Cancer, Vol. 118, No. 6, 2006, pp. 13701380. doi:10.1002/ijc. 21537

[41] H. A. Al-Wadei, M. Majidi, M. S. Tsao and H. M. Schuller, "Low Concentrations of $\beta$-Carotene Stimulate the Proliferation of Human Pancreatic Duct Epithelial Cells in a PKA-Dependent Manner," Cancer Genomics and Proteomics, Vol. 4, No. 1, 2007, pp. 35-42.

[42] W. J. Cunliffe, D. B. Holland, S. M. Clark and G. I. Stables, "Comedogenesis: Some New Aetiological, Clinical and Therapeutic Strategies," The British Journal of Dermatology, Vol. 142, No. 6, 2000, pp. 1084-1091. doi:10.1046/j.1365-2133.2000.03531.x

[43] B. C. Melnik and G. Schmitz, "Role of Insulin, Insulin-Like Growth Factor-1, Hyperglycaemic Food and Milk Consumption in the Pathogenesis of Acne Vulgaris," Experimental Dermatology, Vol. 18, No. 10, 2009, pp. 833-841. doi:10.1111/j.1600-0625.2009.00924.x

[44] C. C. Zouboulis, "Sebaceous Gland Receptors," DermatoEndocrinology, Vol. 1, No. 2, 2009, pp. 77-80.

[45] N. N. Elmongy and O. Shaker, "Expression of Peroxisome Proliferator Activator Receptor $\beta / \delta(\operatorname{PPAR} \beta / \delta)$ in Acne Vulgaris," European Journal of Dermatology, Vol. 22, No. 1, 2012, pp. 42-45.

[46] D. E. Breithaupt and A. Bamedi, "Carotenoid Esters in Vegetables and Fruits: A Screening with Emphasis on $\beta$ Cryptoxanthin Esters," Journal of Agricultural and Food Chemistry, Vol. 49, No. 4, 2001, pp. 2064-2070. doi:10.1021/jf001276t

[47] T. Wingerath, W. Stahl and H. Sies, “ $\beta$-Cryptoxanthin Selectively Increases in Human Chylomicrons upon Ingestion of Tangerine Concentrate Rich in $\beta$-Cryptoxanthin Esters," Archives of Biochemistry and Biophysics, Vol. 324, No. 2, 1995, pp. 385-390. doi:10.1006/abbi.1995.0052

[48] T. Wingerath, H. Sies and W. Stahl, "Xanthophyll Esters in Human Skin," Archives of Biochemistry and Biophysics, Vol. 355, No. 2, 1998, pp. 271-274. doi:10.1006/abbi.1998.0734 